\title{
DESLOCAMENTOS: ESTUDOS NO DUPLO CAMPO DE TRADUÇÃO E ANTROPOLOGIA
}

\author{
Christiane Stallaert \\ Universidades de Antuérpia e Leuven \\ christiane.Stallaert@soc.kuleuven.be \\ christiane.stallaert@artesis.be
}

Evelyn Schuler Zea

Universidade Federal de Santa Catarina

evelynsz@gmail.com

Em julho de 2012 foi realizado em Viena (Áustria) o $54^{\circ}$ Congresso Internacional de Americanistas (ICA), cujo tema foi a "Construção de diálogos nas Américas". A construção de um diálogo implica por definição um movimento tanto de transposição de informação quanto de transferência de significados que no movimento mesmo entre um e outro experimenta um processo de transcodificação. Esta dinâmica transcodificadora constitui crucialmente a tarefa de duas disciplinas, a Antropologia e a Tradução, que, apesar de terem estado sempre intimamente ligadas "em campo", ou seja, tanto na vida real como na prática profissional, foram desenvolvendo-se como áreas acadêmicas separadas, uma no âmbito das Ciências Sociais, a outra no seio da Filologia, seja vinculada à área da literatura comparada, seja vinculada à lingüística. Apenas nas últimas décadas que as zonas de contato entre ambas as disciplinas estão sendo (re)animadas. Uma obra já clássica do ponto de vista desta convergência disciplinar é a de James Clifford \& Geor- 
ge Marcus, Writing Culture. The poetics and politics of ethnography (1986), com contribuições que enfatizam o entrecruzamento da tradução e antropologia (ver, entre outros, Talal Asad, "The Concept of Cultural Translation in British Social Anthropology"). É em diálogo com esta linha de entrelaçamentos entre Antropologia e Estudos de Tradução que se inscreve o presente número temático da Cadernos de Tradução.

A maioria dos textos aqui editados e publicados foi apresentada no simpósio intitulado "Construindo comparações nas Américas: as tarefas da Antropologia e Tradução", coordenado por Christiane Stallaert (Universidades de Antuérpia e Leuven, Bélgica) e Evelyn Schuler Zea (Universidade Federal de Santa Catarina, Brasil), durante o acima mencionado $54^{\circ}$ Congresso Internacional de Americanistas. A reconstrução do diálogo interdisciplinar é o tema central da cooperação entre ambas as coordenadoras que se origina no Acordo Institucional assinado em 2009 entre o Departamento de Tradutores e Intérpretes da Universidade de Antuérpia (Bélgica) e o Programa de Pós-Graduação em Estudos da Tradução (PGET) da Universidade Federal de Santa Catarina. No âmbito desta cooperação tem sido organizado bianulamente um Simpósio de Tradução e Antropologia, com a preciosa mediação e apoio de Andréia Guerini, atual coordenadora do PGET. O primeiro simpósio, em dezembro de 2010, contou com as palestras "Antropologia e Tradução" de Christiane Stallaert e "Modos de transposição na antropologia e na tradução: reflexões a partir de algumas imagens conceituais waiwai" de Evelyn Schuler Zea. No II Simpósio, realizado em abril de 2012, participaram Gabriele Brandstetter, da Universidade Livre de Berlim, com a palestra "Gesto e registro: Arte da ciência?" e Bruna Franchetto, da Universidade Federal do Rio de Janeiro, com a palestra "Línguas ameríndias: modos e caminhos da tradução".

Tal e como mostra a heterogeneidade dos textos neste volume, as zonas de contato entre a Antropologia e os Estudos de Tradução são múltiplas e diversas. Os pontos de conjunção podem ser encon- 
trados em certos conceitos analíticos que migram de uma disciplina para a outra (vale, como exemplo, os conceitos de "transculturação" e de "thick translation"), ou também em certas metodologias de pesquisa, como a etnografia, prática antropológica por excelência que nos últimos anos foi rapidamente conquistando o campo dos Estudos da Tradução. Em outros casos, a ponte de diálogo é constituida pelo próprio pesquisador, cuja formação e dedicação profissional são caracterizadas pela interdisciplinaridade. A Iberoamérica tem sido um terreno fértil para a produção de antropólogos / tradutores, como no caso emblemático - embora não isolado - de José María Arguedas, que também tem uma notável obra como narrador. É mais: desde os inícios históricos da incursão do Ocidente na América resulta impossível dissociar as práticas antropológicas e de tradução como modos de abordar o "outro" neste continente. E se nos aventuramos a formular uma hipótese, poderíamos dizer que foi a partir da sua "reinvenção" ocidental como disciplinas acadêmicas modernas que a Antropologia e a Tradução foram separadas, também nas Américas.

No caminho de reorientação dos Estudos de Tradução na direção de um enfoque cultural, gostariamos de destacar o papel desempenhado pela "escola flamenca", na qual se insere tanto a Universidade de Antuérpia e seu Departamento de Tradutores e Intérpretes criado em 1961, como a Universidade de Leuven, onde em 1989 foi criado o Center for Translation Studies (CETRA). Esta escola também tem um vínculo com o desenvolvimento dos Estudos de Tradução no Brasil, no qual se destaca o papel pioneiro da PGET e sua revista Cadernos de Tradução, criada em 1996 por alguns professores que se formaram na Universidade de Leuven. Em uma obra de referência editada por Theo Hermans, em 1985, The Manipulation of Literature, vários especialistas flamencos como o próprio Theo Hermans, André Lefevere, José Lambert, Hendrik van Gorp, Lieven D'hulst e Raymond van den Broeck contribuiram de modo decisivo para a emancipação de Estudos de Tradução em relação aos estudos estritamente filológico-literários, 
uma condição prévia para sua aproximação posterior a outras áreas das Ciências Humanas, como a Sociologia ou Antropologia.

Após a virada pragmática ("pragmatic turn") dos anos 1970, a virada cultural ("cultural turn") da década de 1980 abriu o caminho para a crescente interdisciplinaridade nos Estudos de Tradução a partir dos anos 90. O fim da Guerra Fria e do mundo bipolar deu um impulso aos processos de globalização, caracterizados pela intensificação dos fluxos e intercâmbios de pessoas, culturas, produtos, ideias e conceitos. Nas Ciências Sociais novos conceitos foram cunhados para descrever as mudanças na ordem social, desde as "comunidades imaginadas" de Benedict Anderson até os "ethno-scapes" de Appadurai. O estudo de realidades localmente enraizadas e supostamente estáveis foi cedendo lugar às análises de conexões, fluxos, fronteiras, hibridizações e creolizações. A pesquisa se reorientou do local/estático como objeto de análise em direção a um maior interesse pelo movimento ou fluxo, produtor de transformação. Essa mudança de enfoque tanto na Antropologia como nos Estudos de Tradução foi registrada em várias obras de referência publicadas no emblemático ano de 1992, V Centenário do "Descobrimento" da América. Alguns exemplos significativos são Mary Louise Pratt, Imperial Eyes. Travel Writing and Transculturation (1992), Tejaswini Niranjana, Siting Translation. History, Post-structuralism, and the Colonial Context (1992), Lawrence Venuti, Rethinking Translation. Discourse, Subjectivity, Ideology (1992), Samia Mehrez, Translation and the colonial experience (1992).

Agora que os antropólogos e tradutólogos voltam a juntar os seus caminhos, será que 500 anos após a chegada dos europeus na América estamos novamente na seção número 1 do jogo de tabuleiro? Esta última é a metáfora usada por Mary Snell-Hornby em seu livro The Turns of Translation Studies (2006) para definir as viradas radicais (U-turns) com os quais se tem caracterizado o desenvolvimento dos Estudos de Tradução no século passado. Apesar de sua aparente radicalidade ou novidade, cada uma destas viradas de meia volta não faz mais do que confrontar-nos com a 
posição de início, ou seja, o dilema fundamental formulado por Schleiermacher no começo do século XIX e reconceitualizado por Berman e Venuti na virada de 1992 como "domesticação" versus "estrangeirização".

De modo crescente percebe-se que a tarefa do antropólogo não é diferente da do tradutor e que ambos, ao longo do desenvolvimento disciplinar, se enfrentam com o mesmo dilema colocado pelo diálogo intercultural, que é a construção de comparações. Comparar - assim como traduzir - implica em criar convergências e homologias entre elementos anteriormente díspares (Michel Callon, 2006, p.32), sem que tal implique a nivelação de suas diferenças. Este tem sido o tema de reflexão proposto aos participantes deste volume: como, a partir das conexões entre ambas as disciplinas, a Antropologia e a Tradução cumprem sua tarefa de construir comparações nas Américas? Cada autor contribuiu com uma resposta parcial a essa pergunta a partir de sua experiência de pesquisa, sua área de interesse e competência profissional. Não buscamos uma homogeneidade de abordagem ou enfoque. Pelo contrário, o presente número temático se apresenta como uma miscelânea, uma composição heterogênea e variada, que servirá como ponto de partida para novos entrelaçamentos e projetos - alguns mais gerais, outros mais específicos -, inspirados por uma preocupação fundamental, a de pensar e reconstruir o diálogo entre antropólogos e tradutores.

Contudo, é possível distinguir através da leitura dos artigos neste volume diferentes estratégias que refletem uma inquietude recorrente: a de situar o que poderíamos chamar provisoriamente o momento ou o lugar da tradução. Assim, o texto de Gabriele Brandstetter, aponta para uma dobra nas configurações compactas tanto da arte como da ciência. Enquanto que esta faz da experiência científica e do protocolo dela um mesmo evento, também na arte rege uma equivalência habitual entre o evento criativo e o modo como ele aparece. Dentro desta engrenagem, Brandstetter localiza um desnível, uma excisão, um Medienwechsel (uma mudança de meios), como instância da tradução de processos criativos. 
No artigo de Bruna Franchetto, por sua vez, se situam as "operações de transfiguração" das traduções no contexto ameríndio tanto nas transposições decorrentes da passagem da tradição oral para sua versão escrita, como nas idas e vindas da escritura entre as línguas indígenas e o português (tomando como caso em análise exercícios tradutivos entre uma língua karib do Alto Xingu - o Kuikuro - e o português).

Um caso de particular importância, também tratado por Franchetto, encontra-se no centro do artigo de Dominique Gallois: as traduções de motivos religiosos nas campanhas de doutrinação dos missionários. $\mathrm{O}$ momento da tradução aparece aqui na colisão simultânea de mundos provocada pela transmissão levada a cabo pelos missionários, já que estes - diferentemente dos antropólogos - não inibem, mas, pelo contrário, colocam em primeiro plano as convicções com as quais pretendem "domesticar" as figuras nativas, como as descritas entre os Wajãpi, os Guarani e os Yanomami.

Neste sentido, a confrontação de mundos na interação cultural que também é desenvolvido no texto de Jean Segata não apenas se reinscreve na descrição etnográfica num âmbito antes explorado por Joanna Overing, também com o motivo da obra de Nelson Goodman, mas que faz desta localização um momento constitutivo da tradução cultural.

Em outro enfoque, o de Sergio Romanelli, Adriano Mafra e Rosane de Souza, o evento da tradução analisado a partir da figura de D. Pedro II aparece como transposição não apenas de uma língua para outra, como, por exemplo, de uma língua nativa ao português, mas também inserida num vasto circuito que vai desde outras línguas europeias até o árabe ou o sânscrito, de modo que mais do que o trânsito limitado entre duas línguas, trata-se na tradução de renovar o modo de circulação em que consiste a vida de línguas.

Em uma escala diferente, é no desdobramento de uma figura conceitual aparentemente homogênea como a "americanidade" onde Marc Charron e Luise von Flotow localizam - em sua análise da tradução de Une histoire américaine, de Jacques Godbout 
(1986), no Brasil - os termos da tradução e a possibilidade de um diálogo frutífero que não exclui os contrastes.

Roseli Barros Cunha, por sua vez, aponta na excepcional obra de José María Arguedas as articulações da tradução, antropologia e criação literária, enfatizando um modo de percepção que permite a transfusão de palavras e coisas; sem dúvida, eis um aspecto da intensa e desasossegada escritura de Arguedas, na qual por outra parte também pode localizar-se o impulso da tradução criativa no campo das tensões políticas: não surpreende, portanto, que as traduções múltiplas e densas de Arguedas sejam uma referencia chave nos ensaios sobre a de/colonialidade do poder (Quijano e outros).

Um aspecto problemático na dinâmica transnacional da teoria, que relega os países periféricos ao consumo dos bens teóricos produzidos nos núcleos predominantes do hemisfério norte, também é tratado por Márcio Seligmann-Silva, apostando na abertura de novos circuitos globais que canalizem - ou seja, que possam traduzir - as figuras da teoria através de "diálogos circulares e em rede".

O texto de Evelyn Schuler Zea, por sua vez, motiva - a partir do processo de composição de La chute du ciel, o livro da liderança yanomami Davi Kopenawa e do antropólogo Bruce Albert - pôr em questão a relação como lugar privilegiado da tradução cultural, especialmente quanto mais se percebe um fator predominante de unidade nas diferentes fórmulas de relação, buscando possíveis alternativas numa lógica das partes, que vê nelas irredutíveis pontos de partida, como zona de emergência da tradução.

Este panorama é, em sua diversidade de instâncias, uma mostra não apenas dos múltiplos registros da tradução, mas talvez também de que ela vive e sobrevive nestes deslocamentos incessantes.

Finalmente, uma Bibliografia parcial do duplo campo de estudos de tradução e antropologia fecha este número especial, abrindo, assim esperamos, terreno para reflexões e desdobramentos vindouros acerca deste campo de estudos em (trans)formação. 
